\title{
Geri Dönüşüm Agregası İçeren Betonarme Düzlem Çerçeve Yapının Performans Değerlendirmesi
}

\section{Performance Assessment of Reinforced Recycled Aggregate Concrete Plane Frame Structure}

\author{
"İlyas Sarıbaş \\ ${ }^{1}$ AAT Bilim ve Teknoloji Üniversitesi, Sarıçam Kampüsü, Adana, TR
}

\begin{abstract}
Özet:
Geri dönüşüm agregası içeren betonun yeni inşa edilen yapılarda kullanılmasına yönelik yapılan çalışmaları destekleyici nitelikte olan bu çalışmada, geri dönüşüm agregası içeren betonarme düzlem çerçeve yapının doğrusal olmayan statik itme analizi yöntemiyle şekildeğiştirme temeline dayalı performans değerlendirmesi yapılmuştır. Yapılan değerlendirme sonucunda elde edilen bulgular normal agregadan üretilen betonarme çerçevenin aynı analiz sonuçları ile karşılaş̧ırılmıştır. Karşılaş̧ırma sonucunda, \%100 oranında kaba geri dönüşüm agregası içeren betonarme çerçevenin performans göstergelerinin doğal agregadan üretilen betonarme çerçevenin performans göstergeleri ile benzer olduğu görülmüştür.
\end{abstract}

Anahtar Kelimeler: Betonarme, Çerçeve, Deprem, Geri dönüşüm agregası, Statik itme analizi.

\begin{abstract}
:
This study has been conducted in order to support the studies intended for using the concrete containing of recycled aggregate in the newly constructed structure. In this study, performance assessment has been made by considering design principles of non-linear static pushover analysis method of reinforced concrete frame structure containing recycle aggregate concrete. The results obtained from the evaluation were compared with the same analysis results of the reinforced concrete frame produced from normal aggregate concrete. As a result of the comparison, the performance indicators of the reinforced concrete frame containing 100\% coarse recycled concrete aggregate were similar to the performance indicators of the reinforced concrete frame produced from natural aggregate.
\end{abstract}

Key words: Reinforced concrete, Frame, Earthquake, Recycled concrete aggregate, Static pushover analysis.

\section{Giriş}

İnşaat ve yıkıntı atığı betonların ortadan kaldırılmasına yönelik çalışmalar ikinci dünya savaşından sonra eski Sovyet Sosyalist Cumhuriyetler Birliği (SSCB), Avrupa Birliği ülkeleri, Japonya ve diğer savaş mağduru ülkeler tarafından hızlı bir şekilde gerçekleştirilmiştir [1-2]. Yapılan çalışmalar sürdürülebilir bir yöntem olan inşaat ve yıkıntı atığı betonların geri dönüştürülmesine olanak sağlamış ve bu dönüştürülen ürün, geri dönüşümlü agrega (GDA) olarak isimlendirilmiştir. Geri dönüşüm yöntemiyle yaklaşık olarak 40 milyon ton GDA SSCB'de yeni yapıların yapımında kullanılmıştır [3]. Aynı yöntemle Almanya, yaklaşık olarak 12 milyon ton GDA ile 175000 adet 
yeni bina inşa etmiştir [4]. Bu gelişmeler ışığında araştırmacılar şu üç temel madde ile ortaya çıkan ve ileride ortaya çıkacak olan atık betonların ortadan kaldırılmasına kesin çözümler bulmaya çalışmaktadırlar;

(a) Atık betondan nasıl daha ekonomik ve kolay bir yolla GDA elde edilebilir,

(b) Geri dönüşümlü agrega nasıl yeni betonda ve yeni yapılan yapıların üretiminde kullanılabilen bir ürün haline getirilebilir,

(c) Sürdürülebilir bir ürün olan GDA'nın kullanımı, yönetmelik ve gerekli hukuki düzenlemelerle nasıl teşvik edilebilir.

$\mathrm{Bu}$ amaçla araştırmacılar tarafından yaklaşık olarak 40 yıldır yoğun deneysel ve analitik çalışmalar yürütülmektedir. Yapılan çalışmalara bakıldığında ise bu çalışmaların büyük bölümünün GDA'nın karakteristik özelliklerinin tespitine yönelik olduğudur. Ayrıca, GDA içeren betonlardan üretilen betonarme yapısal elemanların (kolon, kiriş, döşeme vb.) monoton ve tekrarlı çevrimsel yüklemeler altındaki performansları da bazı araştırmacılar tarafından tespit edilmeye çalışılmıştır [5-14]. Bu çalışmalardan elde edilen genel sonuç ise yeni beton üretiminde GDA oranı arttıkça GDA içeren betonun ve GDA içeren betondan üretilen yapısal elemanların performans göstergelerinin doğal agregadan (DA) üretilen betona ve bu betondan üretilen yapısal elemanların performansına göre belirli oranlarda azaldığıdır. Literatürde GDA içeren betonarme yapıların sismik göstergelerinin ortaya konulmasına yönelik çalışma yok denecek kadar azdır. Bu çalışma ile literatürde sınırlı bilgi düzeyinin olduğu GDA içeren betonarme yapıların deprem performanslarının belirlenmesine yönelik bir çalışma yapılmıştır. Çalışma kapsamında \%100 oranında kaba GDA içeren betondan üretildiği kabul edilen 2 katlı ve 2 açıklıklı düzlem çerçeve betonarme yapı Türkiye Bina Deprem Yönetmeliği'ne (TBDY 2018) [15] göre doğrusal olmayan statik itme yöntemiyle analiz edilmiştir. Yapılan analiz sonucunda elde edilen performans değerleri, benzer yapısal özelliklere sahip olan ve DA ile üretilen betonun kullanıldığı betonarme düzlem çerçeve ile karşılaştırılmıştır.

\section{Analitik Çalışma}

Türkiye Bina Deprem Yönetmeliği 2018'de, deprem etkilerine maruz kalabilecek yapıların deprem yükleri altındaki performanslarının belirlenmesine yönelik bazı yöntemler sunulmaktadır. $\mathrm{Bu}$ çalışmada, deprem yönetmeliğinde sunulan yöntemlerden doğrusal olmayan statik itme yöntemine göre, \%100 oranında kaba GDA içeren 2 katlı ve 2 açıklıklı basit bir düzlem çerçeve betonarme yapının (bu yapı GDA olarak isimlendirilmiştir) şekildeğiştirme temeline dayalı performans değerlendirmesi yapılmıştır. Çalışmanın amacı, GDA içeren betondan üretilen betonarme çerçeve bir yapının performans göstergelerinin DA ile üretilen yapının (bu yap1 DA olarak isimlendirilmiştir) performans göstergelerine benzerliğinin araştırılmasıdır. Ayrıca, çalışma kapsamında analiz edilen her iki yapı da belirtilen yöntemin uygulanabilme koşullarını sağlamaktadır.

\subsection{Taşıyıcı sistemin tanımlanması ve malzeme özellikleri}

Çalışma kapsamında analiz edilen yapılara ait boyutlar ve sisteme etkiyen düşey yükler Şekil 1'de görülmektedir. Depremli durumda sisteme etkiyen sabit $(G)$ ve hareketli (Q) yüklerin toplamı 60 $\mathrm{kN} / \mathrm{m}$ olarak dikkate alınmıştır. Test edilen yapılardaki tüm kolon ve kiriş boyutları benzer olarak seçilmiştir. 


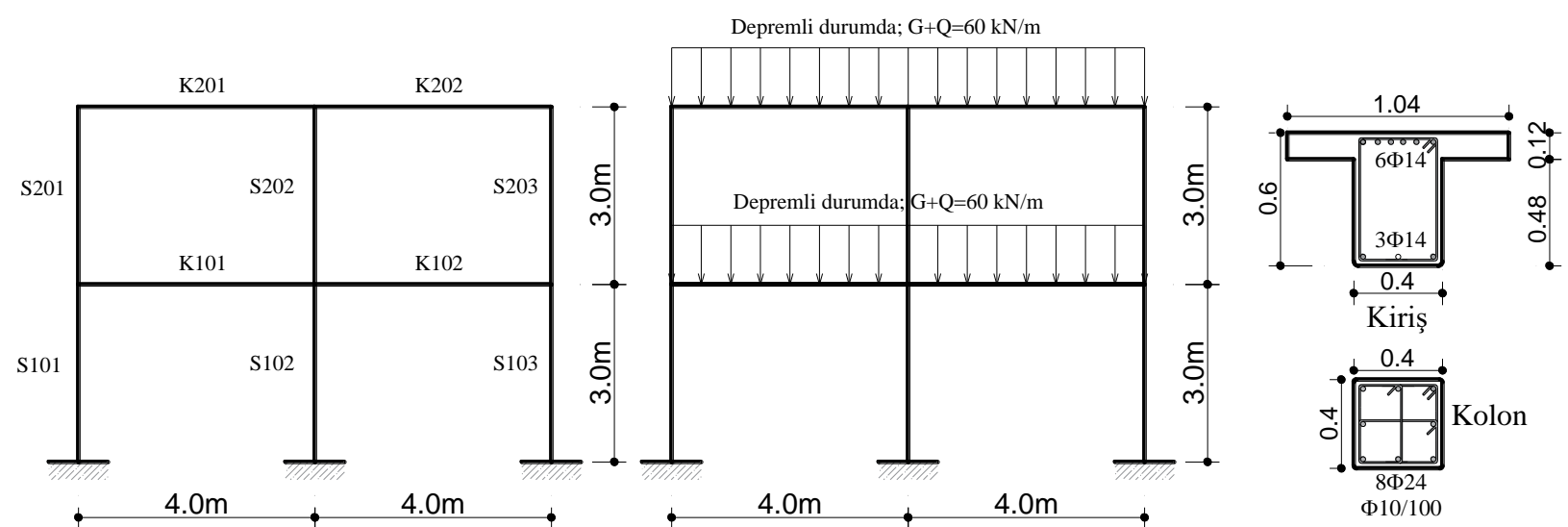

Şekil 1. DA ve GDA yapılarında düşey yükler, şematik düşey kesit, kolon ve kiriş kesitleri (boyutlar m cinsindedir)

Çalışmada doğrusal olmayan yöntemler ile şekildeğiştirmeye göre değerlendirmede kullanılacak olan donatı çeliği olarak TBDY 2018' de tanımlanan B420C donatı çeliği boyuna ve enine donatılar için dikkate alınmıştır. $\mathrm{Bu}$ donatı çeliğine ait gerilme-şekildeğiştirme diyagramı şekil 2a'da verilmiştir. Doğrusal olmayan yöntemler ile şekildeğiştirmeye göre değerlendirmede, sargısız DA ile üretilen beton için Hognestad [16] modeli dikkate alınmıştır. Geri dönüşüm agregası içeren beton için ise Saribas [17] tarafından önerilen GDA içeren betonlar için modifiye edilmiş Hognestad [16] modeli dikkate alınmıştır. Bu modele göre hem DA ile üretilen beton hem de GDA içeren beton için Tablo 1 ve Denklem 1-6 kullanılarak elde edilen beton gerilme-şekildeğiştirme ilişkileri Şekil 2b'de verilmiştir. Ayrıca, sargılı beton modeli için de TBDY 2018'de verilen beton modeli dikkate alınmıştır.

Tablo 1. Yeni betonda ağırlıkça GDA oranına göre i ve s katsayıları

\begin{tabular}{|c|c|c|c|}
\hline Model & $\begin{array}{l}G D A \\
(\%)\end{array}$ & $\begin{array}{c}i \\
\text { katsaylst }\end{array}$ & $\begin{array}{c}s \\
\text { katsaylst }\end{array}$ \\
\hline Hognestad (1951) & 0 & 1.00 & 1.00 \\
\hline Saribas (2019) & 100 & 0.80 & 0.70 \\
\hline \multicolumn{4}{|c|}{$f_{c}=s 0.85 f_{c k}$} \\
\hline \multicolumn{4}{|c|}{$E_{c}=12680+i 460 f_{c}$} \\
\hline \multicolumn{4}{|c|}{$\varepsilon_{c}=\frac{2 f_{c}}{E_{c}}$} \\
\hline \multicolumn{4}{|c|}{$\sigma_{c}=f_{c}\left[\frac{2 \varepsilon_{c}}{\varepsilon_{c o}}-\left(\frac{\varepsilon_{c}}{\varepsilon_{c o}}\right)^{2}\right]$} \\
\hline \multicolumn{4}{|c|}{$f_{c u}=0.85 f_{c}$} \\
\hline & $\varepsilon_{c u}$ & 040 & \\
\hline
\end{tabular}



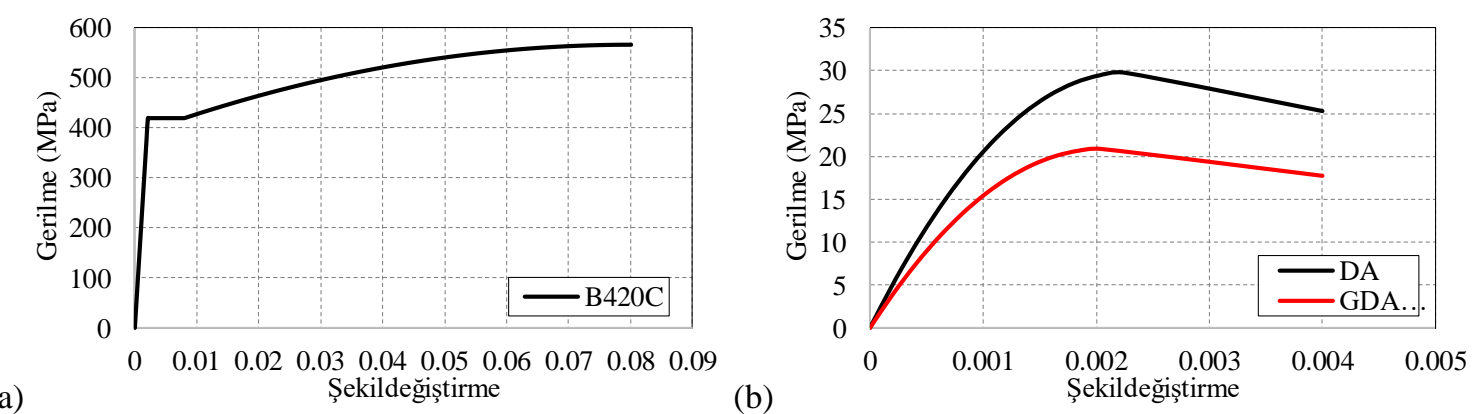

Şekil 2. Beton ve donatı çeliğine ait gerilme-şekildeğiştirme ilişkileri

\subsection{Etkin rijitlikler ve kesit davranışlarının belirlenmesi}

Kolonlarda meydana gelen eksenel yük değerleri (P), deprem hesabında esas alınan toplam kütlelerle uyumlu yüklerin göz önüne alındığı $(G+Q)$ yük birleşiminin ve çatlamamış kesit özelliklerinin kullanıldığı bir ön düşey yük hesabından elde edilmiştir. Bu çalışmada kolon ve kirişler yığılı plastik davranışa göre modellenmiştir. Kolon ve kirişlerin etkin kesit rijitlikleri (EI)e TBDY 2018 Denklem 5.2'ye göre hesaplanmıştır. Etkin rijitliklerin hesabında kullanılan etkin akma moment değerleri, kolonlar için $\mathrm{G}+\mathrm{Q}$ yüklemesinden elde edilen eksenel yüklerin de (Tablo 2) dikkate alınmasıyla XTRACT [18] bilgisayar programı yardımıyla lif analizi yaklaşımı ile elde edilmiştir. Kirişlerin etkin akma momenti kapasiteleri de yine aynı program ve aynı analiz yaklaşımı ile hesaplanmıştır. Kolon ve kiriş kesitlerinin analizinde dikkate alınan beton ve donatı karakteristik değerleri Şekil 2'den görülmektedir. Doğal agrega ve GDA içeren betondan üretilen kolonların moment-eğrilik değerleri Şekil 3a ve Şekil 4a'da verilmiş̧ir. Moment-eğrilik ilişkisinin elastik bölgesi dışında kalan bölge plastik eğrilik olarak tanımlanmaktadır. Plastik eğrilik değerleri TBDY 2018'de tanımlanan plastik mafsal boyu $\left(\mathrm{L}_{\mathrm{p}}=0.5 \mathrm{~h}\right)$ ile çarpılarak moment-plastik dönme ilişkisi elde edilmektedir. Doğal agregalı ve GDA içeren betondan üretilen kolonların plastik kesitleri için moment-plastik dönme ilişkileri Şekil 3b ve Şekil 4b'de verilmiştir. Ayrıca, S103 ve S203 kolonlarının moment-eğrilik ve moment-dönme ilişkileri S101 ve S201 kolonları ile aynı olduğu için şekil 3-4'te bu kolonlara ait değerler verilmemiştir. Geri dönüşüm agregası içeren beton ve DA'lı betondan üretilen kirişlerin plastik kesitleri için (GDA-K, DA-K) moment-eğrilik ve moment-plastik dönme ilişkileri Şekil 5a-5b'de verilmiştir.
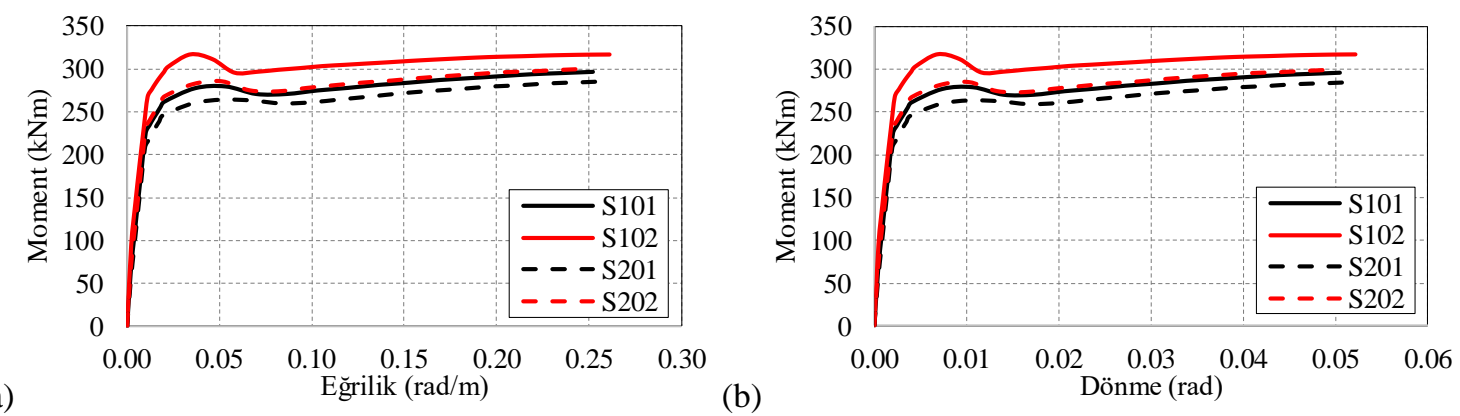

Şekil 3. Doğal agregalı kolonların; (a) Moment-Eğrilik, (b) Moment-Plastik dönme ilişkileri 
(a)

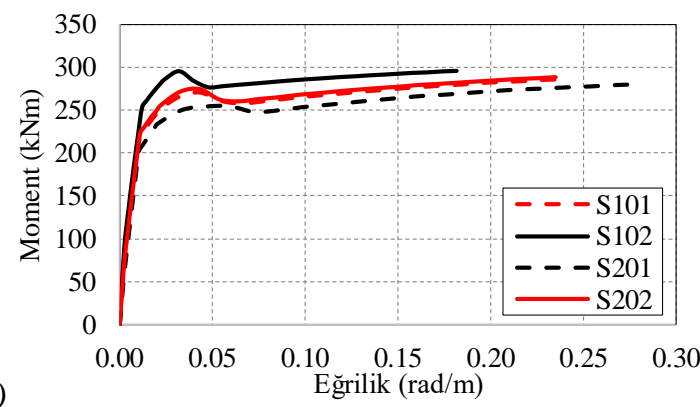

Şekil 4. Geri dönüşüm agregası içeren kolonların;

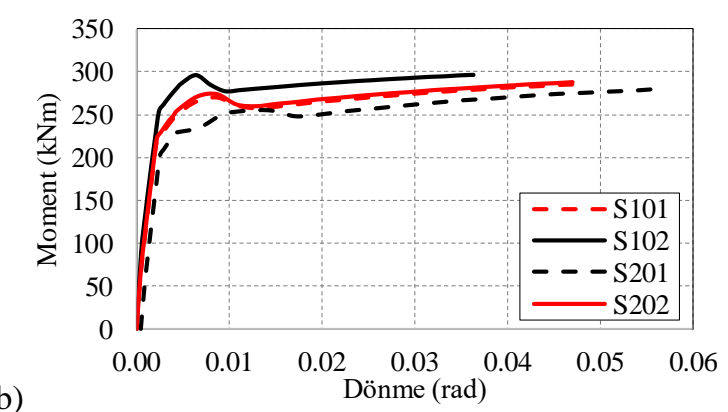

(b)

, (b) Moment-Plastik dönme ilişkileri

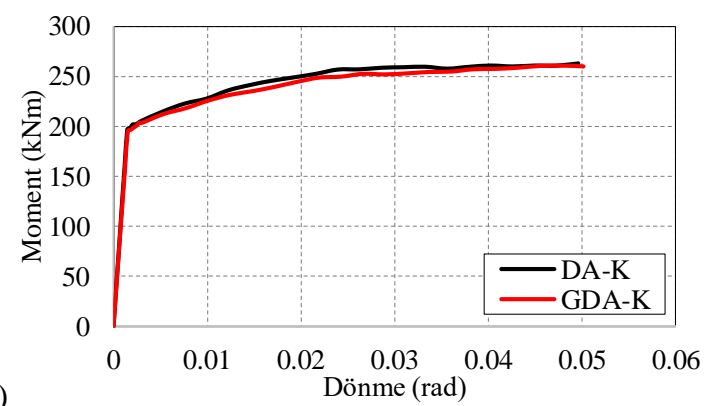

(a)

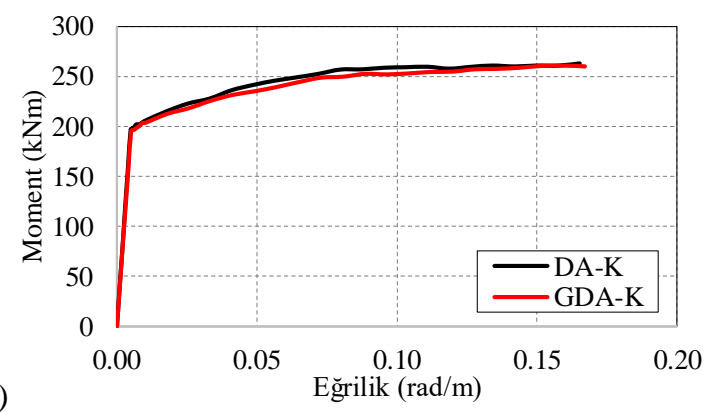

Şekil 5. Kirişlerin; (a) Moment-Eğrilik, (b) Moment-Dönme ilişkileri

Hem GDA hem de DA yapılarındaki kolonların moment-eğrilik, moment-plastik dönme ilişsilerine ek olarak bu yapılardaki kolonların karşılıklı etkileşim diyagramı da XTRACT [18] bilgisayar programı yardımıyla Şekil 6'daki gibi elde edilmiştir.

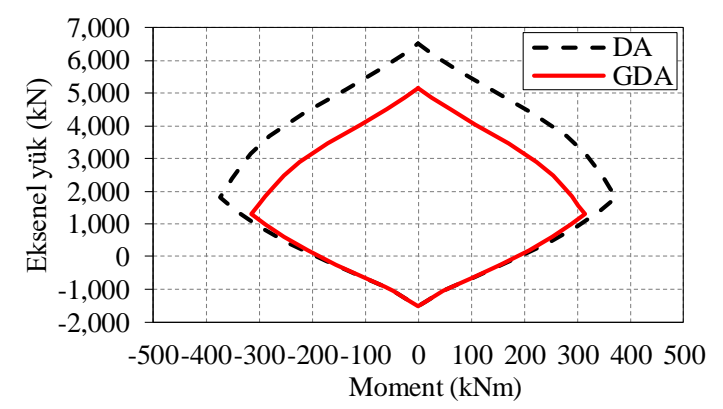

Şekil 6. Kolon karşı1ıklı etkileşim diyagramları

Doğal agrega ve GDA içeren betonların karakteristik özelliklerine sahip kolonlara ait momenteğrilik, moment-dönme ve eksenel yük-moment ilişkilerinden (Şekil 3-4, 6); GDA'lı kolonların eğilme momenti kapasitelerinin DA'lı kolonlarınkinden \%7'e varan oranlarda daha az olduğu görülmektedir. Ayrıca, karşılıklı etkileşim diyagramından (Şekil 6) ise GDA'lı kolonların eksenel yük taşıma kapasitelerinin DA'lı kolonlarınkinden \%23'e varan oranlarda daha düşük olduğu görülmektedir. Hem DA'lı hem de GDA'lı kolonların beton türü hariç tüm özellikleri benzer olduğu için, kapasitelerdeki bu farklılığa neden olan etken DA ve GDA betonlarının beton basınç dayanım farkıdır. Doğal agrega ve GDA içeren betonların karakteristik özelliklerine sahip kirişlere ait moment-eğrilik ve moment-dönme ilişkilerinden (Şekil 5); GDA'lı kirişlerin eğilme momenti kapasitelerinin DA'lı kirişlerinkine benzer olduğu görülmektedir. Eğilme kritik elemanlarda (kiriş, 
döşeme), ekstrem durumlar dışında davranışta eğilme donatısı etken olduğu için beton davranışta daha az etkilidir. Dolayısıyla DA ve GDA içeren betonlar arasında \%30'a varan dayanım farkı olmasına rağmen DA'lı ve GDA'lı kirişlerin moment-eğrilik ve moment-dönme değerleri benzer olarak elde edilmiştir.

Yapılardaki kiriş ve kolonlara ait etkin akma momentleri (Şekil 3-5) kullanılarak etkin rijitlikler hem DA hem de GDA yapıları için Tablo 3'te olduğu gibi elde edilmiştir. Doğrusal olmayan statik itme analizine başlamadan önce hem GDA hem de DA yapılarındaki kolon ve kirişler için yapılan ön hesaplamalar sonucu elde edilen etkin kesit rijitlikleri ilgili yapısal elemana tanımlanmıştır. Ayrıca, yine ön hesaplamalar sonucunda elde edilen plastik mafsal özellikleri deprem etkileri altında en çok zorlanan kiriş ve kolonların uçlarına yerleştirilmiştir. Doğrusal olmayan statik itme analizi Sap 2000 [19] yazılımı ile yapıldığı için programda varsayılan plastik mafsal özellikleri ve etkin rijitlik değerleri kullanılmayarak bu değerler hesapla elde edilen değerlerle (Şekil 3-5 ve Tablo 3) revize edilmiştir.

\begin{tabular}{|c|c|c|c|c|c|c|c|}
\hline Yapt & Kolon & $\begin{array}{c}P \\
(k N)\end{array}$ & $\begin{array}{c}b \\
(m)\end{array}$ & $\begin{array}{c}h \\
(m)\end{array}$ & $\begin{array}{c}A_{c} \\
\left(m^{2}\right)\end{array}$ & $\begin{array}{c}f_{c} \\
(M P a)\end{array}$ & $P /\left(P_{o}=A_{c} f_{c}\right)$ \\
\hline \multirow{6}{*}{$D A$} & S101 & 267.6 & \begin{tabular}{l|l}
0.4 \\
\end{tabular} & 0.4 & 0.16 & 30 & 0.06 \\
\hline & $S 102$ & 623.6 & \begin{tabular}{ll|}
0.4 \\
\end{tabular} & 0.4 & 0.16 & 30 & 0.13 \\
\hline & S103 & 267.6 & 0.4 & 0.4 & 0.16 & 30 & 0.06 \\
\hline & $S 201$ & 131.9 & 0.4 & 0.4 & 0.16 & 30 & 0.03 \\
\hline & S202 & 315.5 & \begin{tabular}{ll|}
0.4 \\
\end{tabular} & 0.4 & 0.16 & 30 & 0.07 \\
\hline & $S 203$ & 131.9 & $\begin{array}{l}0.4 \\
0.4\end{array}$ & 0.4 & 0.16 & 30 & 0.03 \\
\hline \multirow{6}{*}{$G D A$} & $S 101$ & \begin{tabular}{|l|l|}
273.0 \\
\end{tabular} & \begin{tabular}{l|l}
0.4 \\
\end{tabular} & 0.4 & 0.16 & 21 & 0.08 \\
\hline & $S 102$ & 612.7 & \begin{tabular}{ll|}
0.4 \\
\end{tabular} & 0.4 & 0.16 & 21 & 0.18 \\
\hline & S103 & 273.0 & 0.4 & 0.4 & 0.16 & 21 & 0.08 \\
\hline & $S 201$ & 133.4 & \begin{tabular}{|c|}
0.4 \\
\end{tabular} & 0.4 & 0.16 & 21 & 0.04 \\
\hline & $S 202$ & 312.4 & $\begin{array}{l}0.4 \\
\end{array}$ & 0.4 & 0.16 & 21 & 0.09 \\
\hline & $S 203$ & 133.4 & $\begin{array}{l}0.4 \\
\end{array}$ & 0.4 & 0.16 & 21 & 0.04 \\
\hline
\end{tabular}

Tablo 3. Etkin kesit rijitlikleri

\begin{tabular}{c|cc}
\hline \multirow{2}{*}{ Eleman } & $D A$ & $G D A$ \\
\cline { 2 - 3 } & $(E I)_{e}$ & $(E I)_{e}$ \\
\hline S101, S103 & 0.270 & 0.260 \\
S102 & 0.280 & 0.280 \\
S201, S203 & 0.250 & 0.240 \\
S202 & 0.270 & 0.260 \\
K101, K102 & 0.080 & 0.075 \\
K201, K202 & & \\
\hline
\end{tabular}

\section{Doğrusal olmayan statik itme analizi}

Doğrusal olmayan statik itme analizinin başlangıç adımında doğrusal elastik davranış için hesaplanan birinci doğal titreşim periyotları DA ve GDA yapıları için sırasıyla $T_{1, D A}=0.73 \mathrm{~s}$, $\mathrm{T}_{1, \mathrm{GDA}}=0.84 \mathrm{~s}$ olarak etkin kütle katılım oranları ise her iki yapı için 0.90 olarak gerçekleşmiştir. Dolayısıyla yöntemin uygulanabilme koşullarından birisi olan etkin kütle katılım oranının en az 0.70 olma koşulu sağlanmış olmaktadır (Tablo 4). Eşdeğer deprem yükü dağılımı her katta deprem doğrultusundaki hâkim doğal titreşim mod şekli genliği ile ilgili kütlenin çarpımından elde edilen değerle $\left(\mathrm{m}_{\mathrm{i}} \Phi_{\mathrm{i} 1}\right)$ orantılı olacak şekilde yapılara uygulanmaktadır (Tablo 4, Şekil 7). Doğrusal olmayan statik itme analizi Sap 2000 [19] yazılımı ile yapılmıştır. Analiz sonucunda hem GDA 
hem DA yapıları için elde edilen taban kesme kuvveti-yerdeğiştirme ilişkileri Şekil 8a'da verilmiştir.

Tablo 4. Etkin kütle katılım oranları ve eşdeğer deprem yükü dağılımları

\begin{tabular}{|c|c|c|c|c|c|c|c|c|}
\hline Yapı & Kat & $\Phi_{i 1}$ & $m_{i}$ & $m_{i} \Phi_{i 1}$ & $m_{i} \Phi_{i 1^{2}}$ & $M_{x l}$ & $\Gamma_{x l}$ & $E K O$ \\
\hline \multirow{3}{*}{$D A$} & 1 & 0.060 & 59.20 & 3.60 & 0.213 & \multirow{3}{*}{104.90} & \multirow{3}{*}{10.00} & \multirow{3}{*}{$0.90>0.70$} \\
\hline & 2 & 0.120 & 57.50 & 6.90 & 0.828 & & & \\
\hline & & $\Sigma$ & 116.70 & 10.50 & 1.041 & & & \\
\hline \multirow{3}{*}{$G D A$} & 1 & 0.058 & 59.10 & 3.50 & 0.203 & \multirow{3}{*}{104.40} & \multirow{3}{*}{10.20} & \multirow{3}{*}{$0.90>0.70$} \\
\hline & 2 & 0.117 & 57.20 & 6.70 & 0.796 & & & \\
\hline & & $\Sigma$ & 116.30 & 10.20 & 0.999 & & & \\
\hline
\end{tabular}

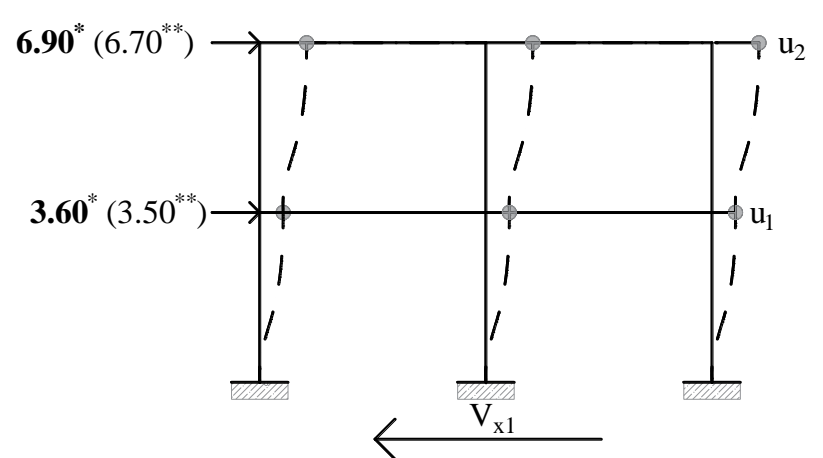

Şekil 7. Eşdeğer deprem yükü dağılımı (*: DA yapısında uygulanan, **: GDA yapısında uygulanan; Tablo 4'e bakinız)

Çözümleme sonucunda elde edilen taban kesme kuvveti-tepe yerdeğiştirme eğrisinden faydalanılarak, hâkim moda ait modal kapasite diyagramı; modal ivme (a $1 / \mathrm{g})$-modal yerdeğiştirme $\left(\mathrm{d}_{1}\right)$ olarak elde edilmiştir (Şekil $8 \mathrm{~b}$ ). Doğrusal olmayan analizin yapıldığı yapıların deprem performansının belirlenmesinde TBDY 2018'e göre deprem yer hareketi düzeyi DD-2, 50 yılda aşılma olasılığ $1 \% 10$ (tekrarlanma periyodu 475 yıl) olan deprem yer hareketi düzeyi seçilmiştir. Yerel zemin sınıfı ZC olan bölgenin konumu; Enlem: 37.194421', Boylam: 36.54689 olarak belirlenmiştir. Bu özelliklere sahip konumun kısa periyot harita spektral ivme katsayısı $\left(\mathrm{S}_{\mathrm{s}}\right)$ 0.887, 1.0 saniye periyot için harita spektral ivme katsayısı $\left(\mathrm{S}_{1}\right) 0.240$, kısa periyot tasarım spektral ivme katsayısı $\left(\mathrm{S}_{\mathrm{DS}}\right)$ 1.064, 1.0 saniye periyot için tasarım spektral ivme katsayısı $\left(\mathrm{S}_{\mathrm{D} 1}\right) 0.360$ olarak belirlenmiştir. Ayrıca bu konuma ait en büyük yer ivmesi (PGA) 0.374 g, en büyük yer hızı (PGV) $23.216 \mathrm{~cm} / \mathrm{s}$ olarak elde edilmiştir.
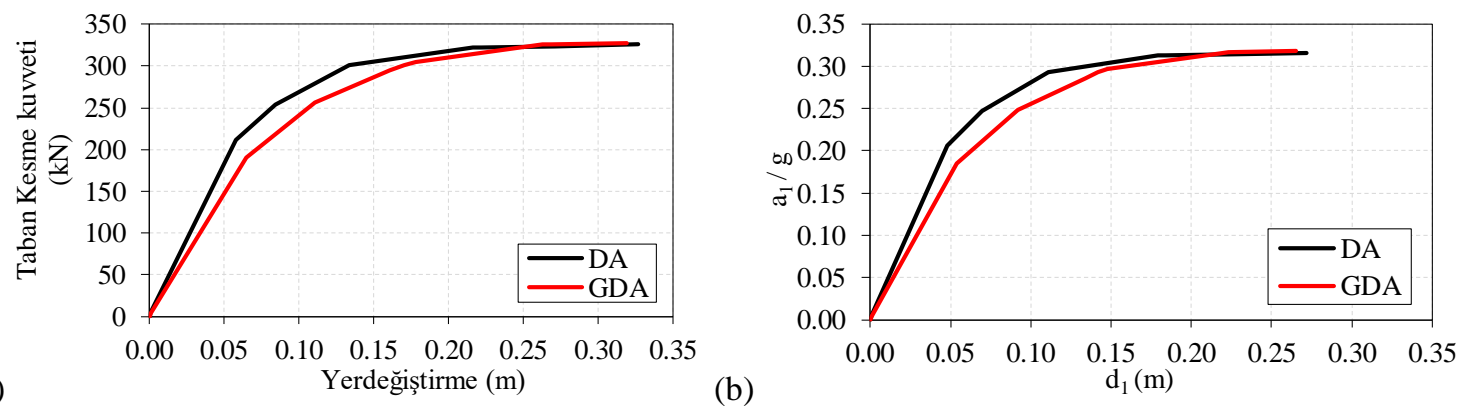

(a)

(b)

Şekil 8. DA ve GDA yapılarında; (a) Taban kesme kuvveti-Tepe yerdeğiştirme ilişkileri, (b) Modal kapasite diyagramı 
Yukarıda tanımlanan yer hareketi düzeyi için yatay elastik istem spektrumunun (EİS) ordinatları olan yatay elastik tasarım spektral ivmeleri $S_{\text {ae }}(T)$ doğal titreşim periyoduna bağlı olarak yerçekimi ivmesi (g) cinsinden, yatay elastik tasarım spektral yerdeğiştirmeleri $S_{d e}(T)$ doğal titreşim periyoduna bağlı olarak metre (m) cinsinden elde edilmiştir (Şekil 9).

Geri dönüşüm agregası içeren yapı ve DA'lı yapıların hakim titreşim modlarına ait doğal titreşim periyotları $\mathrm{T}_{1, \mathrm{DA}}=0.73 \mathrm{~s}, \mathrm{~T}_{1, \mathrm{GDA}}=0.84 \mathrm{~s}$, ilgili konuma ait zemin sinıfına ait spektrum periyodu $\mathrm{T}_{\mathrm{B}}=0.34 \mathrm{~s}$ 'den daha büyük olduğu için eşit yerdeğiştirme kuralına göre $\mathrm{T}_{1, \mathrm{DA}}, \mathrm{T}_{1, \mathrm{GDA}}$ periyotlarına karşıl1k gelen yerdeğiştirmeler $\left(\mathrm{S}_{\mathrm{de} 1}\right) \mathrm{d}_{1, \mathrm{DA}}=0.065 \mathrm{~m}, \mathrm{~d}_{1, \mathrm{GDA}}=0.074 \mathrm{~m}$ olarak belirlenmiştir. Deprem doğrultusunda meydan gelen tepe yerdeğiştirme istemleri $\left(\mathrm{u}_{\mathrm{xN}}\right)$ ise DA ve GDA yapıları için sırasıyla $0.079 \mathrm{~m}$ ve $0.090 \mathrm{~m}$ olarak hesaplanmıştır.

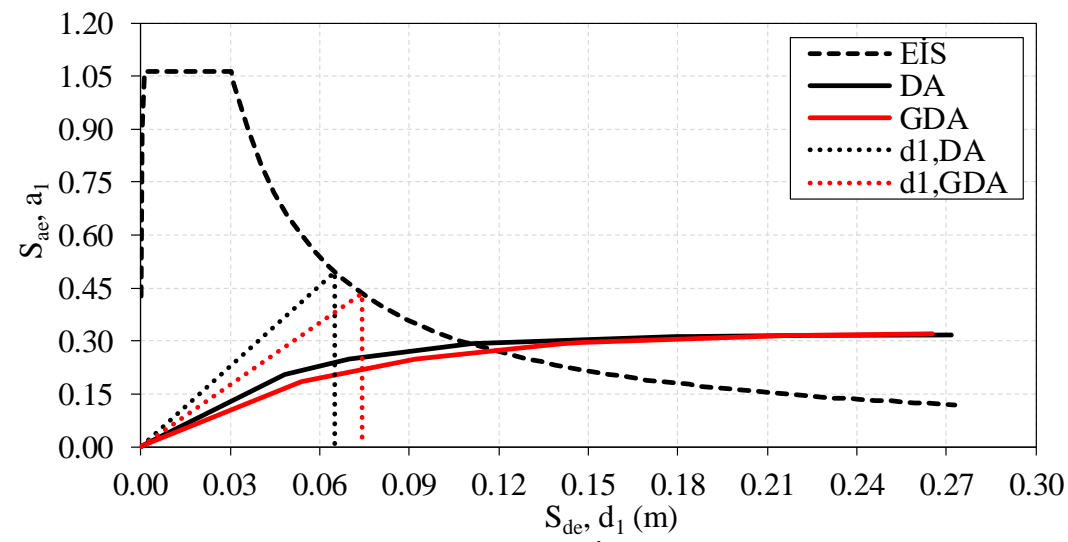

Şekil 9. DA ve GDA yapılarında elastik istem spektrumu (EİS) ve modal kapasite spektrumlarının örtüştürülmesi

Hem DA hem de GDA yapılarında tepe yerdeğiştirme istemine karşı gelen durumda her iki sistem üzerinde oluşan plastik mafsallar ve oluşma sırası Şekil 10'da görülmektedir. Aynı yapıların tepe yerdeğiştirme istemine karşı gelen kiriş ve kolon moment ve kesme kuvveti değerleri Şekil 11'de verilmiştir.

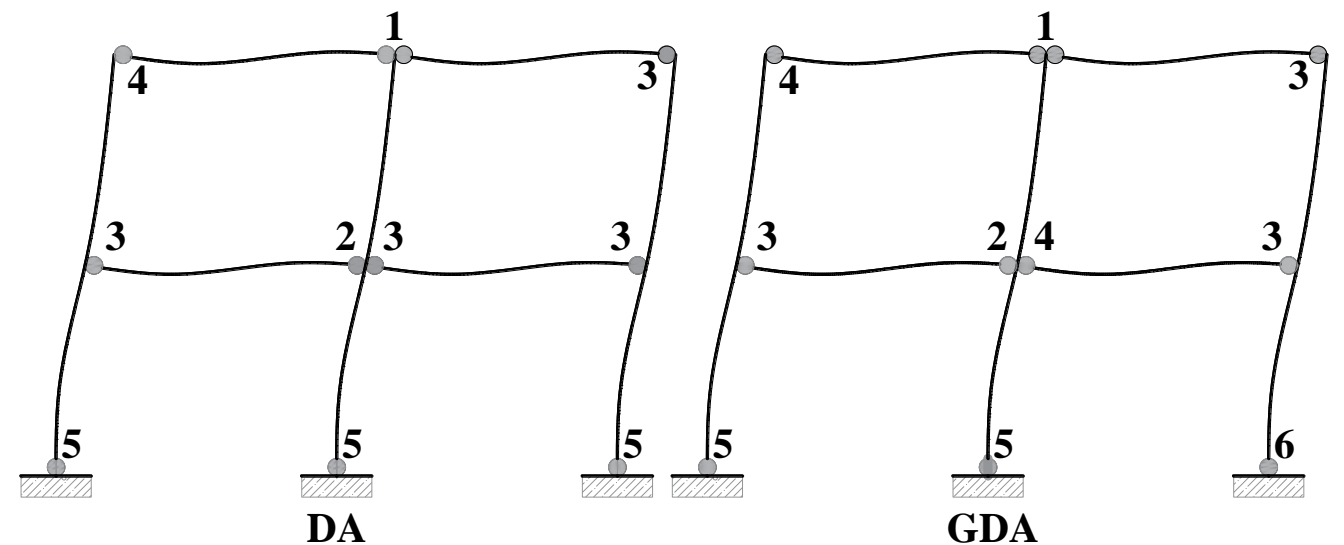

Şekil 10. Yapılarda meydan gelen mafsallar ve oluşma sırası

Gevrek davranışa ilişkin iç kuvvet istemlerinin, iç kuvvet kapasiteleri ile karşılaştırılması gerekmektedir. $\mathrm{Bu}$ amaçla doğrusal olmayan itme analizinde tepe yerdeğiştirme istemine karş1 gelen itme adımındaki eleman kesme kuvvet değerleri TS 500'e [20] göre belirlenen kesme kuvveti dayanımları ile karşılaştırılmıştır. Kesme kuvvetinin karşılanmasında betonun kesme kuvveti 
taşımadığı kabul edilmiştir. Buna göre hem DA hem de GDA yapıları için kesme kuvveti dayanımları kirişler ve kolonlarda sırasıyla, $\mathrm{V}_{\mathrm{r}}=363.0 \mathrm{kN}, \mathrm{V}_{\mathrm{r}}=336.5 \mathrm{kN}$, olarak elde edilmiştir. Deprem yüklemesi durumunda kolon ve kirişlerde meydana gelen kolon ve kiriş kesme kuvveti değerleri (Şekil 11) ile hesaplanan kapasite kesme kuvveti değerleri karşılaştırıldığında tüm elemanların gevrek olarak hasar görmeyen eleman olarak sınıflandırılabileceği görülmektedir. Kolon kiriş birleşim bölgeleri için TBDY 2018 Denklem 7.11'e göre hesaplanacak $V_{e}$ kesme kuvveti isteminin kesme dayanımını aşmaması gerekmektedir. Buna örnek olarak hem DA hem GDA yapılarında S102, S202, K101, K102 birleşim bölgesi dikkate alınarak hesaplan deprem kesme kuvveti istemleri sırasıyla $\mathrm{V}_{\mathrm{e}, \mathrm{DA}}=619 \mathrm{kN}, \mathrm{V}_{\mathrm{e}, \mathrm{GDA}}=617 \mathrm{kN}$ olarak hesaplanmıştır. Birleşim, kuşatılmış birleşim olduğu için TBDY 2018 Denklem 7.12'ye göre yapılan hesaplamada deprem kesme kuvveti kapasiteleri hem DA hem de GDA yapılarında ilgili birleşim bölgesi için sırasıyla $\mathrm{V}_{\mathrm{e}, \mathrm{DA}} \leq 8160 \mathrm{kN}, \mathrm{V}_{\mathrm{e}, \mathrm{GDA}} \leq 5712 \mathrm{kN}$ olarak hesaplanmıştır. Bu sonuçlarla beraber, deprem yüklemesi durumunda kolon ve kirişlerde meydana gelen kolon ve kiriş deprem kesme kuvveti istemi değerleri ile hesaplanan kapasite deprem kesme kuvveti değerleri karşılaştırıldığında tüm elemanların $\mathrm{V}_{\mathrm{e}}$ kesme kuvveti isteminin deprem kesme dayanımını aşmadığı görülmüş dolayısıyla her iki yapıdaki tüm elemanlar gevrek olarak hasar görmeyen eleman olarak sınıflandırılabilmiştir.

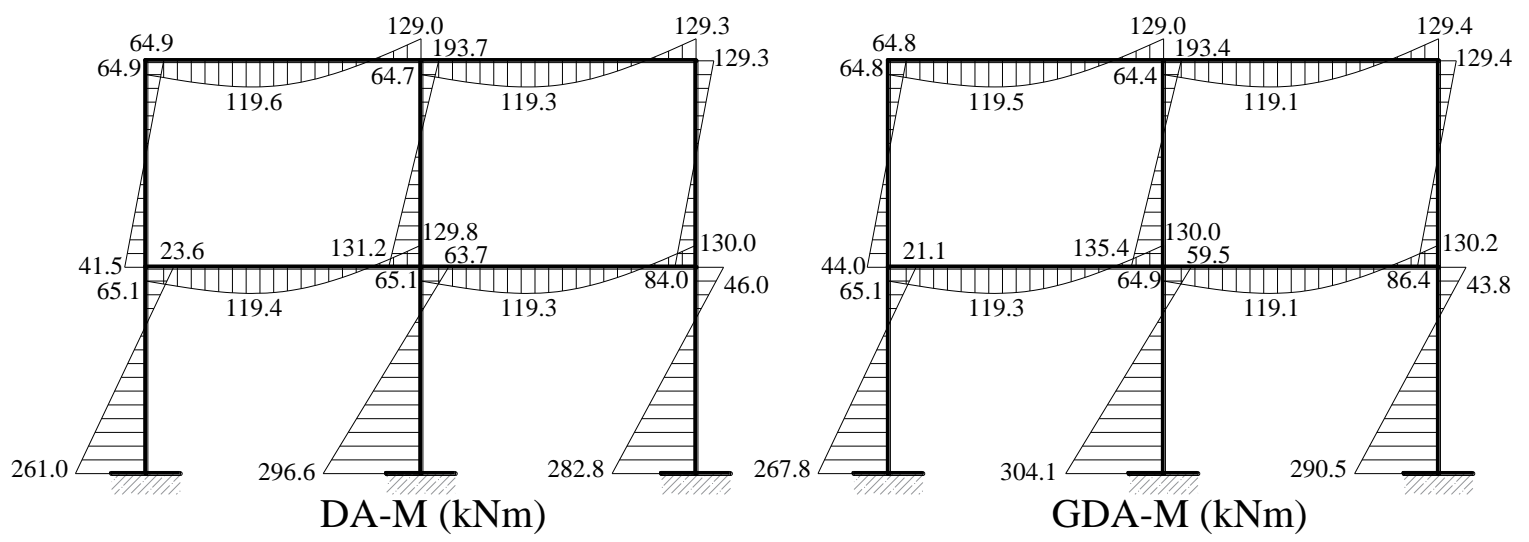

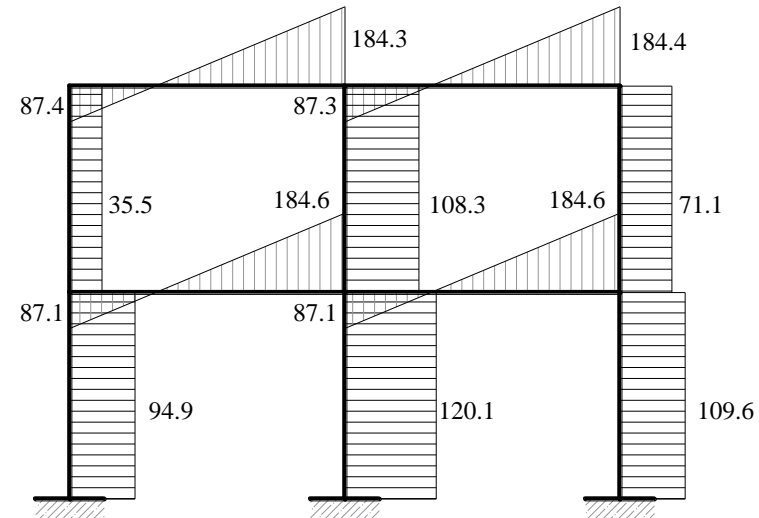

$\mathrm{DA}-\mathrm{V}(\mathrm{kN})$

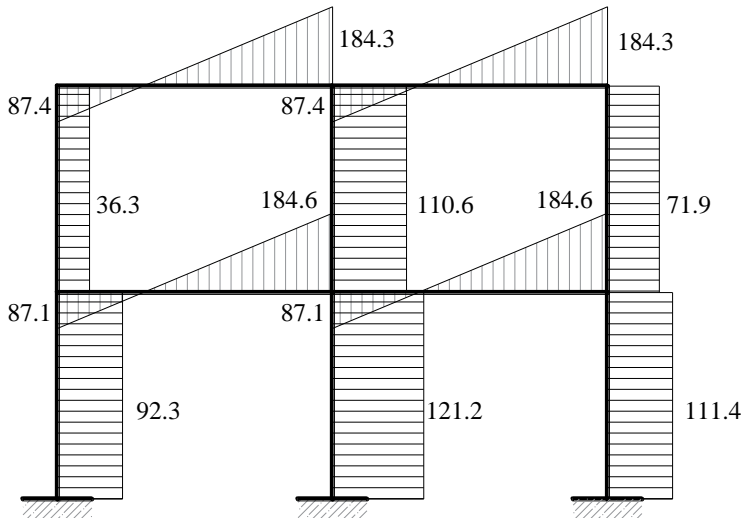

GDA-V $(\mathrm{kN})$

Şekil 11. DA ve GDA yapılarında moment ve kesme kuvveti oluşumları 
Tablo 5. Kolon ve kirişlerde şekildeğiştirme ve plastik dönmeler

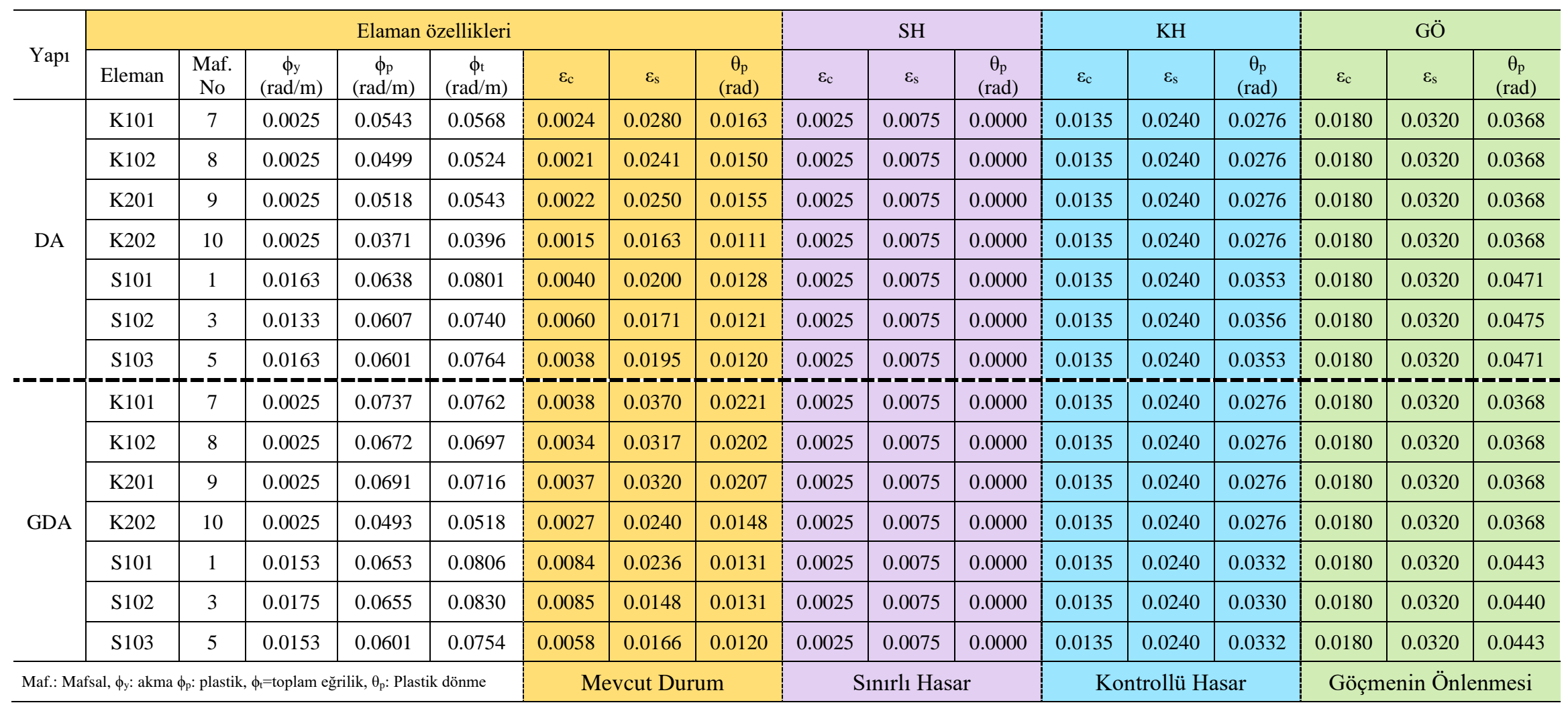


Türkiye Bina Deprem Yönetmeliği 2018'de Bina Performans Hedeflerinin tanımına esas olmak üzere, deprem etkisi altında bina taşıyıcı sistemleri için Bina Performans Düzeyleri; Kesintisiz Kullanım (KK) Performans Düzeyi: Bu performans düzeyi, bina taşıyıcı sistem elemanlarında yapısal hasarın meydana gelmediği veya hasarın ihmal edilebilir ölçüde kaldığı duruma karşı gelen, Sınırlı Hasar (SH) Performans Düzeyi: Bu performans düzeyi, bina taşıyıcı sistem elemanlarında sınırlı düzeyde hasarın meydana geldiği, diğer deyişle doğrusal olmayan davranışın sınırlı kaldığı hasar düzeyine karşı gelen, Kontrollü Hasar (KH) Performans Düzeyi: Bu performans düzeyi, can güvenliğini sağlamak üzere bina taşıyıcı sistem elemanlarında çok ağır olmayan ve çoğunlukla onarılması mümkün olan hasar düzeyine karşı gelen, Göçmenin Önlenmesi (GÖ) Performans Düzeyi: Bu performans düzeyi, bina taşıyıcı sistem elemanlarında ileri düzeyde ağır hasarın meydana geldiği göçme öncesi duruma karşı gelen ve binanın kısmen veya tamamen göçmesi önlenmiş olarak tanımlanmaktadır.

Yapılan çalışma kapsamında hem DA hem de GDA yapılarının performans düzeylerini belirlemek için Tablo 5'te verilen ve plastikleşmenin meydana geldiği yapısal elemanlar için hesaplanan değerler kesit hasar sınırları (SH, KH, GÖ) ile karşılaştırılmıştır. Yapıların performans düzeyleri kesitlerde oluşan hasarın durumu ile direk bağlantılı olduğu için yapılan karşılaştırma sonucunda hem DA hem de GDA yapılarının “Kontrollü Hasar” performans düzeyinde olduğu görülmüştür.

\section{Sonuçlar}

Bu çalışma kapsamında geri dönüşüm agregası içeren (GDA) ve geri dönüşüm agregası içermeyen (DA) iki yapının deprem yükleri altındaki performansı değerlendirilmiştir. Elde edilen verilere göre GDA içeren betonun ve DA'lı betonun dayanım ve elastisite modülleri arasında önemli oranda fark olmasına rağmen bu iki yapının taban kesme kuvvet-yerdeğiştirme eğrilerinin benzer olduğu görülmektedir. $\mathrm{Bu}$ eğrilerde GDA yapısına ait rijitlik kaybına neden olan etken ise GDA içeren betonun elastisite modülüdür. Değerlendirmede her iki yapının da tüm performans göstergelerinin benzer olduğu görülmüştür.

$\mathrm{Bu}$ çalışma, GDA içeren betonun malzeme yönetmelik kriterlerini sağlayacak şekilde üretilmesi, yap1 ve deprem yönetmelik kriterlerini sağlayacak şekilde bir yapıda kullanılabilmesi durumuna kolay ve anlaşılır bir örnektir. Yazar bu ve benzeri çalışmaların hem ülkemizde hem de dünyada yaygınlaşmasıyla sürdürülebilir bir ürün olan GDA'nın kullanımının yaygınlaşacağını ümit etmektedir.

\section{Teşekkür}

Yazar bu metni okuyup gerekli düzenlemelerin yapılmasında emeği geçen Mustafa TOLUN'a Teşekkür eder.

\section{Referanslar}

[1] Nixon PJ. Recycled concrete as an aggregate for concrete-A review. Mater Struct. 1978;11(6):371-78. 
[2] Topcu BL, Guncan Firat N. Using waste concrete as aggregate. Cem Concr Res. 1995; 25 (7):1385-90.

[3] Gluzhge PJ. The work of scientific research institute. Gidrotekhnicheskoye Stroitel'stvo. No. 4, April 1946; 27-8.

[4] Hansen TC. Recycling of Demolished Concrete and Masonry. E\&FN SPON, (1992), London, U.K.

[5] Shi XS, Wang QY, Qiu CC, Zhao XL. Mechanical properties of recycled concrete filled steel tubes and double skin tubes. In: 2nd International conference on waste engineering and management-ICWEM 2010 RILEM proceedings, 73:559-67.

[6] Fathifazl G, Razaqpur AG, Abbas OB, Fournier B, Foo S. Shear capacity evaluation of steel reinforced recycled concrete (RRC) beams without stirrups. Eng. Struct. 2011; 33(3):1025-1033.

[7] Xiao J, Huang X, Shen L. Seismic behavior of semi-precast column with recycled aggregate concrete. Const. Build. Mat. 2012; 35:988-1001.

[8] Sindy SP, Belen GF, Javier EL. Bond behavior of steel reinforcement and recycled concrete. Mat. Struct. 2013; 47:323-334.

[9] Ma H, Xue J, Luo D, Zhang X. Seismic performance of steel-reinforced recycled concrete columns under low cyclic loads. Const. and Build. Mat. 2013; 48:229-237.

[10] Ma H, Xue J, Liu Y, Zhang X. Cyclic loading tests and shear strength of steel reinforced recycled concrete short columns. Eng. Struct. 2015; 92:55-68.

[11] Rise N, De Brito J, Correia JR, Arruda MRT. Punching behavior of concrete slabs incorporating coarse recycled concrete aggregates. Eng. Struct. 2015; 100:238-248.

[12] Soleimani F, McKay M, Yang CSW, Kurtis KE, DesRoches R, Kahn LF. Cyclic testing and assessment of columns containing recycled concrete debris. ACI Struct. J. 2016; 113(5):10091020.

[13] Goksu C, Saribas I, Binbir E, Akkaya Y and Ilki A. Structural performance of recycled aggregates concrete sourced from low strength concrete. Structural Engineering and Mechanics, 2019; 69(1):77-93.

[14] Saribas I, Goksu C, Binbir E, Ilki A. Seismic performance of full-scale RC columns containing high proportion recycled aggregate. Bull. Earthquake Eng. 2019 https://doi.org/10.1007/s10518019-00687-0.

[15] TBDY 2018. Türkiye Bina Deprem Yönetmeliği 2018, AFAD, Ankara, Türkiye.

[16] Hognestad E. A study of combined bending and axial load in reinforced concrete members. University of Illinois Bulletin. 1951; 49:22.

[17] Saribas I. Stress-strain Model for Recycled Aggregate Concretes. El-Cezerî Journal of Science and Engineering, 2019; 6(1):156-165.

[18] XTRACT (Computer software), Rancho Cordova, CA, TRC.

[19] SAP2000, CSI Inc., Berkeley, USA, 2010.

[20] TS 500 (2000) Betonarme yapıların tasarım ve yapım kuralları, TSE, Ankara, Türkiye. 